\title{
Application of modern ASUDD solutions on the example of Shchors street, Belgorod
}

\author{
Nikolay Zagorodniy ${ }^{1 *}$, Alexey Borovskoy ${ }^{1}$, Olga Borovskaya ${ }^{1}$ and Evgeny Novopisny ${ }^{1}$ \\ ${ }^{1}$ Federal state educational institution of higher education «Belgorod state technological University \\ named V.G. Shukhov» (BSTU named V.G. Shukhov) 308012, Russia, Belgorod, st. Kostyukova 46
}

\begin{abstract}
ASUDD solutions is considered on the example of Shchors Street in Belgorod. Field studies of traffic flows were carried out. When modeling the considered area, an increase in the load was revealed. A traffic light layout plan has been developed. It is established that due to the control of the traffic flow in the lanes with the help of ASUDD solutions, the redistribution of traffic flows in the directions is achieved.
\end{abstract}

\section{Introduction}

As the practice of the authors shows in the creation of traffic management projects without the use of modern solutions in the field of ASUDD, it is impossible to implement the constructive decisions taken. Significant changes in traffic intensity during the day, their redistribution as a result of the "human" factor, the creation of a priority for public transport, all this requires an instant response in the settings of traffic light objects $[5,11]$. At the same time, due to the complexity of the objects, it is often necessary to implement up to 128 signal groups in one controller. Let's consider solutions in the field of ASUDD on the example of Shchors Street, Belgorod.

\section{Analysis of decisions in the field of ASUDD on the example of Shchors street}

One of the most difficult intersections along the entire street. Shchorsa of Belgorod is st. Gubkin [13]. At this intersection, there are both public transport stops (2 units) and regulated entry and exit from the territory of the shopping center. The traffic organization diagram is shown in Figure 1.

This ODD scheme was developed on the basis of modeling existing traffic flows using field studies carried out before the start of the reconstruction. The results of which are shown in Table 1 (rush hour - morning) [1,4].

\footnotetext{
* Corresponding author: n.zagorodnij@yandex.ru
} 


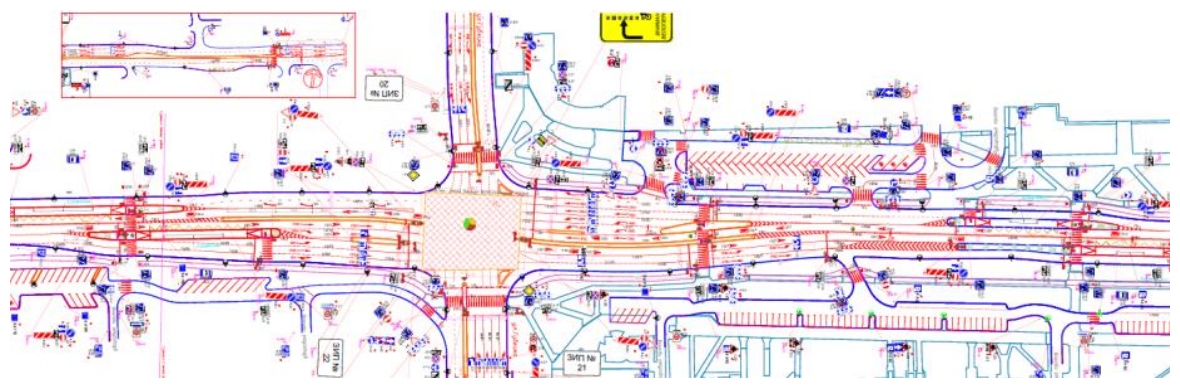

Fig. 1. ODD scheme at the intersection of st. Shchorsa - st. Gubkina

Table 1. Field research form in the morning rush hour

\begin{tabular}{|c|c|c|c|c|c|c|c|c|c|c|c|c|}
\hline \multirow[b]{2}{*}{ Direction } & \multicolumn{3}{|c|}{$\begin{array}{c}\text { Shalandina Street } \\
\text { (from the east) }\end{array}$} & \multicolumn{3}{|c|}{$\begin{array}{c}\text { Budennogo Street } \\
\text { (from the west) }\end{array}$} & \multicolumn{3}{|c|}{$\begin{array}{l}\text { Shchorsa Street } \\
\text { (from the north) }\end{array}$} & \multicolumn{3}{|c|}{$\begin{array}{l}\text { Shchorsa Street } \\
\text { (from the south) }\end{array}$} \\
\hline & 2 & $\widehat{\uparrow}$ & $\vec{r}$ & 5 & $\widehat{\uparrow}$ & 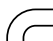 & $\sqrt{2}$ & $\widehat{\widehat{r}}$ & $\Rightarrow$ & $\sqrt{7}$ & 们 & $\Rightarrow$ \\
\hline $\begin{array}{l}\text { Type of } \\
\text { transport }\end{array}$ & \multicolumn{12}{|c|}{ units / hour } \\
\hline $\begin{array}{c}\text { Passenger } \\
\text { car (units / } \\
\text { hour) }\end{array}$ & 174 & $\begin{array}{c}332 \\
4\end{array}$ & $\begin{array}{c}221 \\
0\end{array}$ & $\begin{array}{c}221 \\
6\end{array}$ & $\begin{array}{c}330 \\
6\end{array}$ & $\begin{array}{c}226 \\
4\end{array}$ & $\begin{array}{c}220 \\
4\end{array}$ & $\begin{array}{c}334 \\
2\end{array}$ & $\begin{array}{c}116 \\
2\end{array}$ & 448 & $\begin{array}{c}331 \\
8\end{array}$ & 778 \\
\hline Cargo $(<2 \mathrm{t}$.) & 0 & 24 & 0 & 12 & 18 & 0 & 0 & 0 & 0 & 0 & 0 & 0 \\
\hline Cargo (2-6t.) & 0 & 18 & 0 & 0 & 0 & 6 & 0 & 0 & 0 & 0 & 0 & 0 \\
\hline Cargo (>6t.) & 0 & 0 & 0 & 0 & 0 & 6 & 0 & 0 & 0 & 0 & 0 & 0 \\
\hline Road Train & 0 & 0 & 0 & 0 & 0 & 0 & 0 & 0 & 0 & 0 & 0 & 0 \\
\hline Minibus & 6 & 0 & 0 & 0 & 6 & 6 & 0 & 18 & 12 & 12 & 6 & 0 \\
\hline Small bus & 0 & 0 & 0 & 60 & 0 & 0 & 12 & 0 & 36 & 0 & 24 & 0 \\
\hline $\begin{array}{l}\text { The bus is } \\
\text { big }\end{array}$ & 0 & 0 & 0 & 18 & 0 & 0 & 0 & 6 & 6 & 0 & 10 & 0 \\
\hline $\begin{array}{l}\text { Articulated } \\
\text { bus }\end{array}$ & 0 & 0 & 0 & 0 & 0 & 0 & 0 & 0 & 0 & 0 & 0 & 0 \\
\hline $\begin{array}{l}\text { Number of } \\
\text { pedestrians }\end{array}$ & \multicolumn{3}{|c|}{0} & \multicolumn{3}{|c|}{0} & \multicolumn{3}{|c|}{0} & \multicolumn{3}{|c|}{0} \\
\hline
\end{tabular}

In addition to the hour-long studies, "Infopro" transport detectors were installed on the site, which provided data on the intensity of each lane of traffic (Figure 2) [14,16].

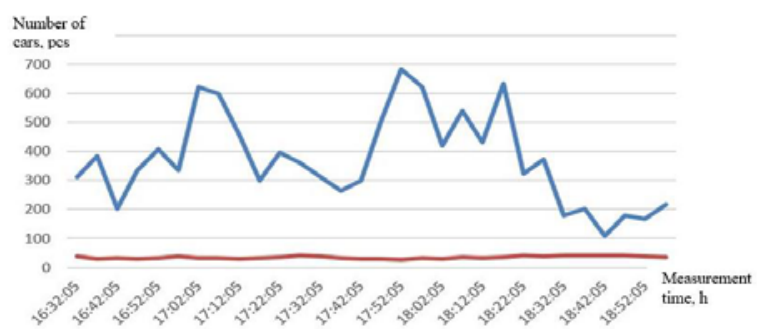

Fig. 2. Diagram of traffic intensity on Shchorsa Street in one lane during the evening rush hour. Infopro Detector 
Using the obtained data, the simulation of both the existing situation and the newly designed one for this section was carried out, which showed an increase in the load on Gubkin Street (ACCORDING to Aimsun) [2,3]. The intersection of the section is shown in Figure 3.
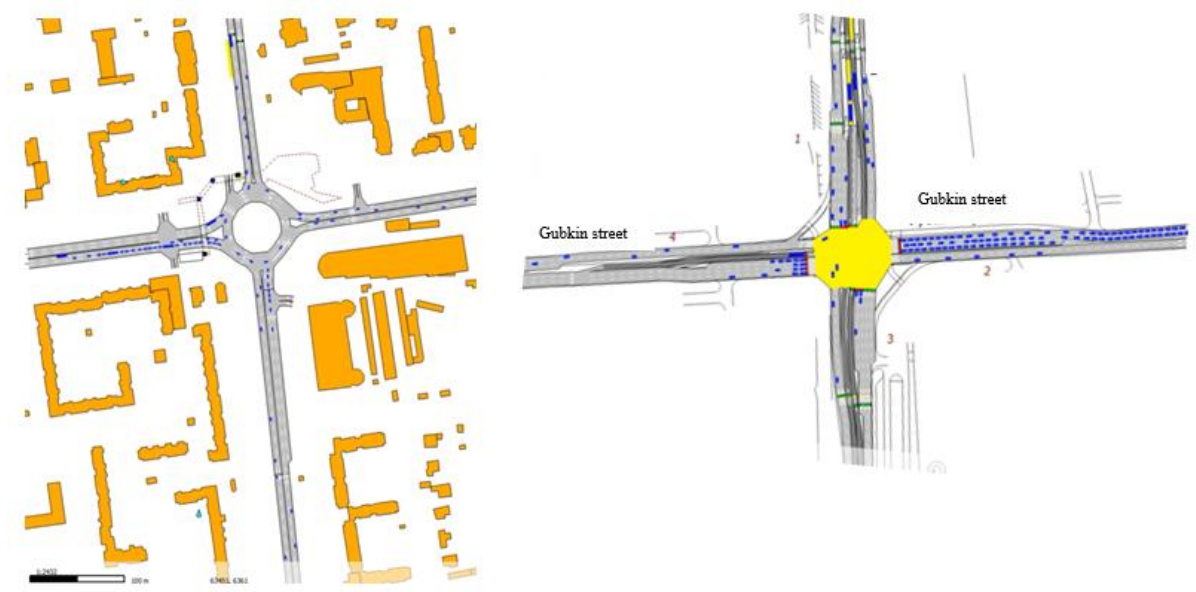

Fig. 3. Simulation models of the existing and projected intersection

Comparative analysis showed an increase in the speed of public transport by 2 times and a decrease in the speed of personal transport by 1.2 times [6,17]. Based on the obtained results of modeling IP Pashnev O. A., a plan for the placement of traffic lights was developed, shown in Figure 4 [10].
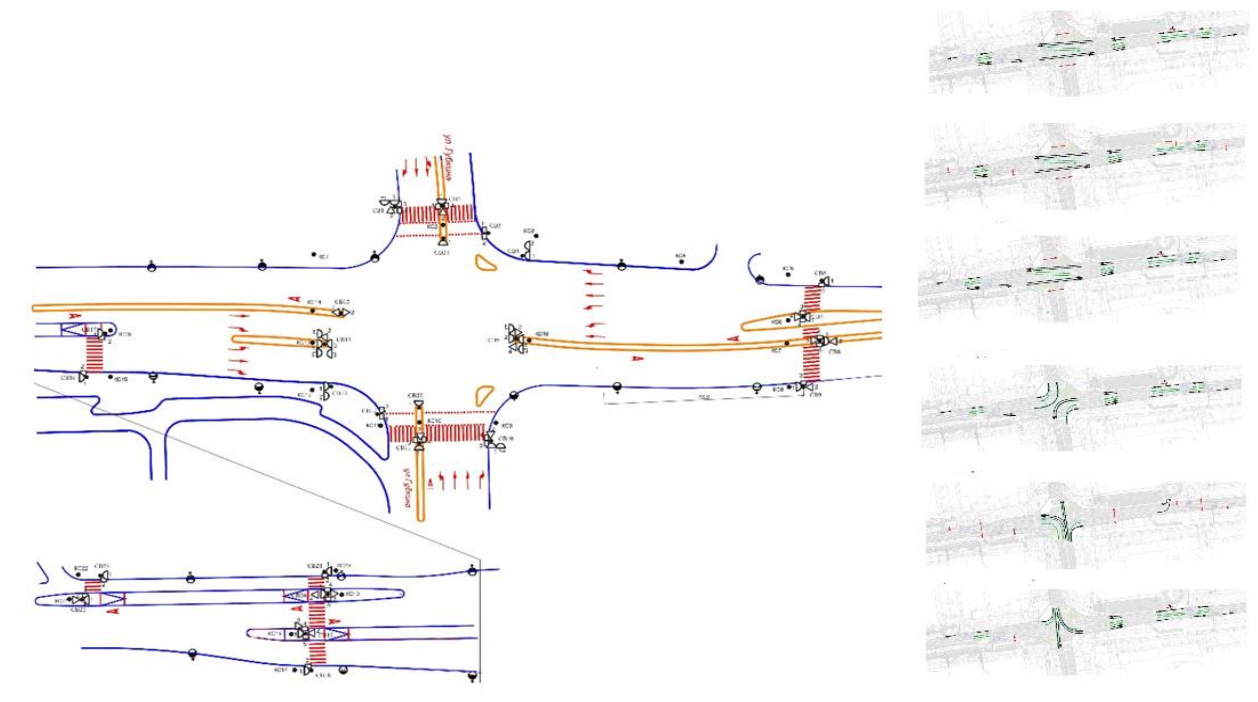

Fig. 4. Traffic light layout plan at the intersection of Shchors st. - Gubkin st.

Based on the accepted layout of the equipment, a number of requirements for controllers and software were formulated: 124 ;

1. The maximum possible number of channels supported by the controller is at least

2. Ability to implement coordinated adaptive management from the center; 
3. The ability to connect different types of detectors.

In addition to the above requirements, an additional list of comparative data was formulated:

* the ability to adjust the direction of movement (please briefly describe the implementation - is there a limit on the number of phases that can be recorded in the DC);

* limit on the number of phases used in the cycle;

* the ability to change the sequence of phases both when working on a calendar schedule, and on a call (dispatcher, call with TVP, working out a call at certain readings from the detector, etc.));

* the number of control programs recorded in the DC itself, the technology of recording programs in the DC (directly on the site, via remote access using Ethernet, creating a library of control programs both by time of day, by days of the week and seasons). Describe the procedure for loading and selecting control programs including those using the Automated Control System APM;

* ability to set changeable proms.clock cycles (when working with different phase sequences, using a matrix of inter-green, universal proms.Implementation of conflict control during the development of the prom.clock cycles;

- when using local adaptive control, the following parameters can be adjusted:

minimum and maximum cycle time;

minimum and maximum phase or direction time;

minimum and maximum break time;

gap reduction time;

the time from the beginning of the phase after which the gap begins to decrease; the number of cars after which the gap begins to decrease;

dynamic maximum (the ability to increase the maximum phase time at high load).

- if you use an adaptive control algorithm that uses a number of other parameters, please provide information about the algorithm and the parameters that an ASUDD engineer can work with [18].

List of questions about working with ASUDD:

* the ability to create new switching programs using the phases used by the DC. There is a limit on the number of programs. The ability to use third-party resources to download new programs.

* The ability to maintain coordinated management on the UDS site (one street or network) with adaptive management on one or more objects.

* The ability to adjust parameters such as: the cycle time for the UDS section (minimum and maximum), the setting of the master object for which time correction is provided, the parameters for which the phase correction occurs on the slave objects with rigid or adaptive control;

* identification of the average flow rate to create the coordination of the $\mathrm{CO}$ operation, including the calculation of the time shift of the leading phase assignment.

- if you use an adaptive network management algorithm that uses a number of other parameters, please provide information about the algorithm and the parameters that the ASUDD engineer can interact with

* the ability to remotely change the configuration of the road controller with the control of the transmission of the corresponding network commands.

* the ability to create traffic priorities, coordination, etc. along the length of the vehicle queue at the approaches to the intersection [7,9].

Based on the selection of equipment, the following types of controllers were considered, presented in Table 2 [8]. 
Table 2. Analysis of controllers according to the given criteria

\begin{tabular}{|c|c|c|c|c|}
\hline \multirow[t]{2}{*}{ Criteria } & \multicolumn{4}{|c|}{ The controller } \\
\hline & $\begin{array}{l}\text { "CASCADE" } \\
\text { (characteristics, } \\
\text { RE) }\end{array}$ & $\begin{array}{l}\text { DKSMN-S3-16, } \\
\text { DKSMN-S3-24 } \\
\text { (characteristics) }\end{array}$ & $\begin{array}{l}\text { "KDSF SPECTRUM" } \\
\text { (Linux) (features, RE) }\end{array}$ & $\begin{array}{c}\text { KDU } 3.3 \\
\mathrm{~N} \\
\text { (technical } \\
\text { description } \\
\text { and RE) } \\
\end{array}$ \\
\hline \multicolumn{5}{|c|}{ Traffic light control algorithm } \\
\hline $\begin{array}{l}\text { Phase-by-phase control } \\
\text { (including adaptive } \\
\text { control-MGR) }\end{array}$ & yes & yes & yes & no \\
\hline $\begin{array}{l}\text { Formation of a promtact } \\
\text { based on the full matrix } \\
\text { of intergreenmatrix } \\
\text { InterGreenMatrix }\end{array}$ & no & no & $\begin{array}{l}\text { yes, up to } 64 \text { directions } \\
\text { (signal groups) }\end{array}$ & no \\
\hline $\begin{array}{l}\text { Local adaptive (active) } \\
\text { direction control }\end{array}$ & no & no & $\begin{array}{l}\text { yes, multi-ring mode with } \\
\text { direction control, control of } \\
\text { the" break "of the flow with } \\
\text { "intelligent" change in the } \\
\text { trigger threshold, queue } \\
\text { control for the time of the } \\
\text { forbidding signal, dynamic } \\
\text { maximum green, } \\
\text { coordination mode, priority } \\
\text { pass }\end{array}$ & no \\
\hline $\begin{array}{l}\text { Unified algorithm for } \\
\text { local adaptive regulation }\end{array}$ & no & no & $\begin{array}{l}\text { advanced Full-Actuated } \\
\text { MultiRing controller } \\
\text { algorithm (described by } \\
\text { HCM2000) }\end{array}$ & no \\
\hline $\begin{array}{c}\text { Priority travel (priority } \\
\text { mode) }\end{array}$ & no & no & $\begin{array}{l}\text { yes, according to the arrival } \\
\text { forecast or the activation of } \\
\text { the call and exit detector of } \\
\text { the zone }\end{array}$ & no \\
\hline $\begin{array}{c}\text { Local situational } \\
\text { management }\end{array}$ & no & yes & $\begin{array}{c}\text { yes (arbitrary logic is set by } \\
\text { user scripts) }\end{array}$ & no \\
\hline $\begin{array}{l}\text { different algorithm for } \\
\text { local adaptive control }\end{array}$ & no & $\begin{array}{l}\text { delay detection; } \\
\text { congestion } \\
\text { detection; local, } \\
\text { anti-congestion } \\
\text { control }\end{array}$ & no & no \\
\hline \multicolumn{5}{|c|}{ Library of SP signal plans } \\
\hline $\begin{array}{l}\text { Maximum number of } \\
\text { phases }\end{array}$ & 8 & $\begin{array}{l}\text { up to } 16 \text { phases, } \\
\text { up to } 72 \\
\text { directions }\end{array}$ & Not limited & no \\
\hline $\begin{array}{c}\text { Maximum number of } \\
\text { phases in SP }\end{array}$ & - & - & Not limited & - \\
\hline Maximum number of SP & 8 & 32 & Not limited & 34 \\
\hline Calendar Settings & $\begin{array}{l}\text { daily plan, weekly } \\
\text { schedule }\end{array}$ & $\begin{array}{c}\text { daily plan, days } \\
\text { of the week, } \\
\text { month }\end{array}$ & $\begin{array}{c}\text { daily schedule, weekly } \\
\text { schedule, seasonal schedule, } \\
\text { special days of the year }\end{array}$ & $\begin{array}{l}\text { daily plan, } \\
\text { days of the } \\
\text { week }\end{array}$ \\
\hline $\begin{array}{c}\text { Number of calendar } \\
\text { entries }\end{array}$ & - & - & Not limited & 34 \\
\hline \multicolumn{5}{|c|}{ Properties of an open information system } \\
\hline $\begin{array}{c}\text { Unified entities of } \\
\text { algorithms, control } \\
\text { parameters, and } \\
\text { controller configurations }\end{array}$ & no & no & $\begin{array}{l}\text { Yes, in the concept of a } \\
\text { multi-ring controller (Full- } \\
\text { Actuated multiring } \\
\text { controller) }\end{array}$ & no \\
\hline $\begin{array}{c}\text { Open machine-readable } \\
\text { configuration } \\
\text { description format }\end{array}$ & no & no & JSON & no \\
\hline
\end{tabular}


As can be seen from the analysis, only the equipment of the company "RIPAS" meets the advanced requirements [15]. In addition to it, radar detectors were installed, allowing not only to monitor the traffic flow along the lanes, but also to determine the length of the queue (Figure 5).

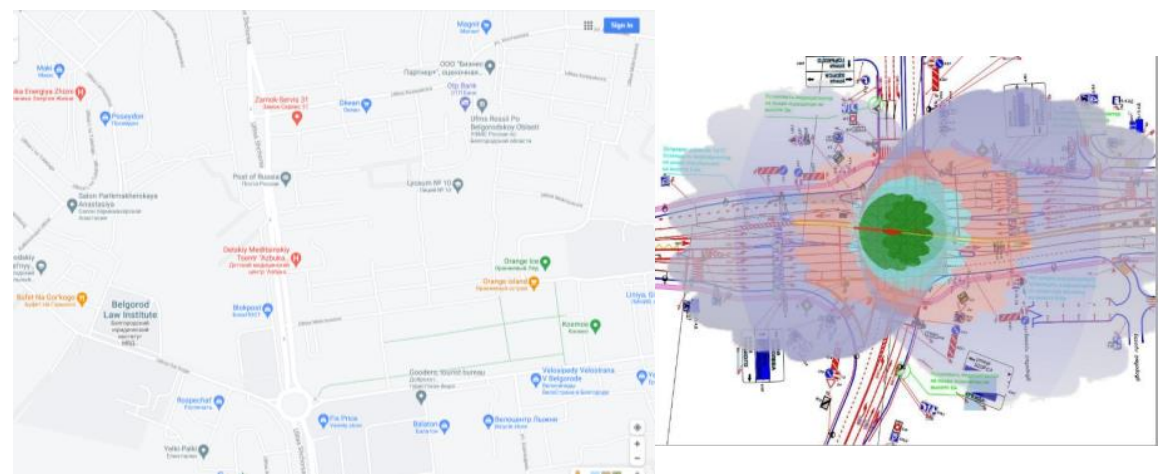

Fig. 5. The area of coverage of the intersection with radar detectors of transport

After the opening of traffic on Shchorsa Street, the following results were obtained for the traffic flow, shown in Figures 6, 7.

Fig. 6.

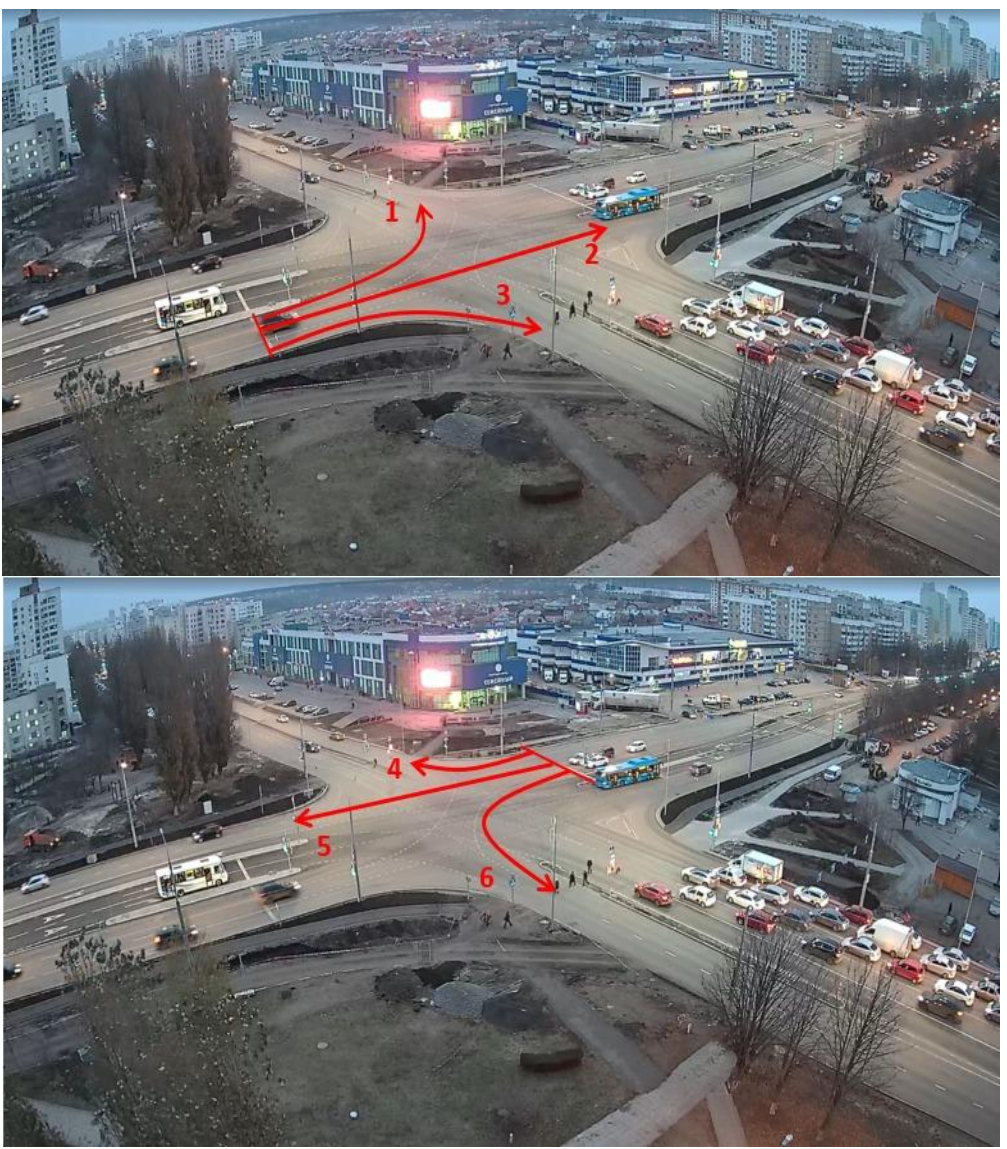

Reallocation of traffic flows in the following directions 

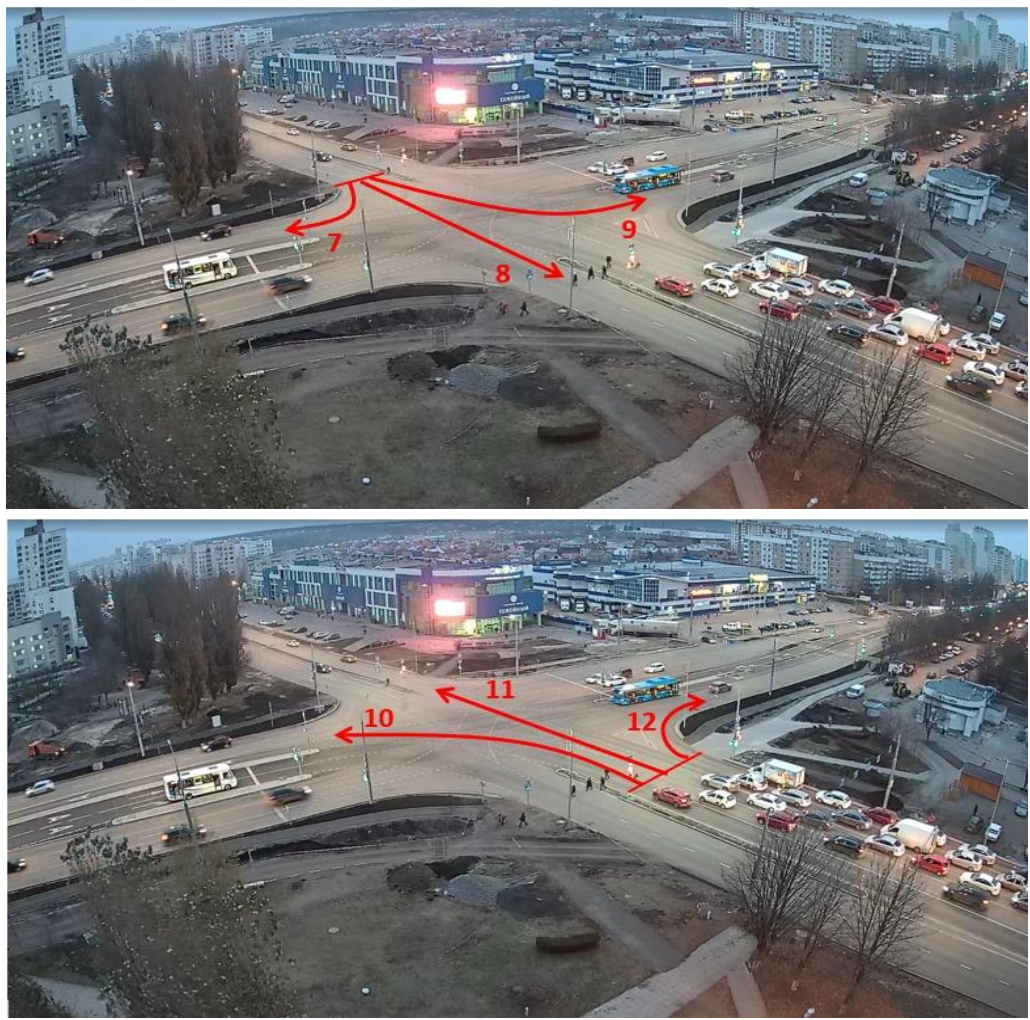

Fig. 7. Reallocation of traffic flows in the following directions

As can be seen from the presented data, the total load has not changed much, but there has been a significant redistribution of traffic flows in the directions, the graph of which is shown in Figure 8.

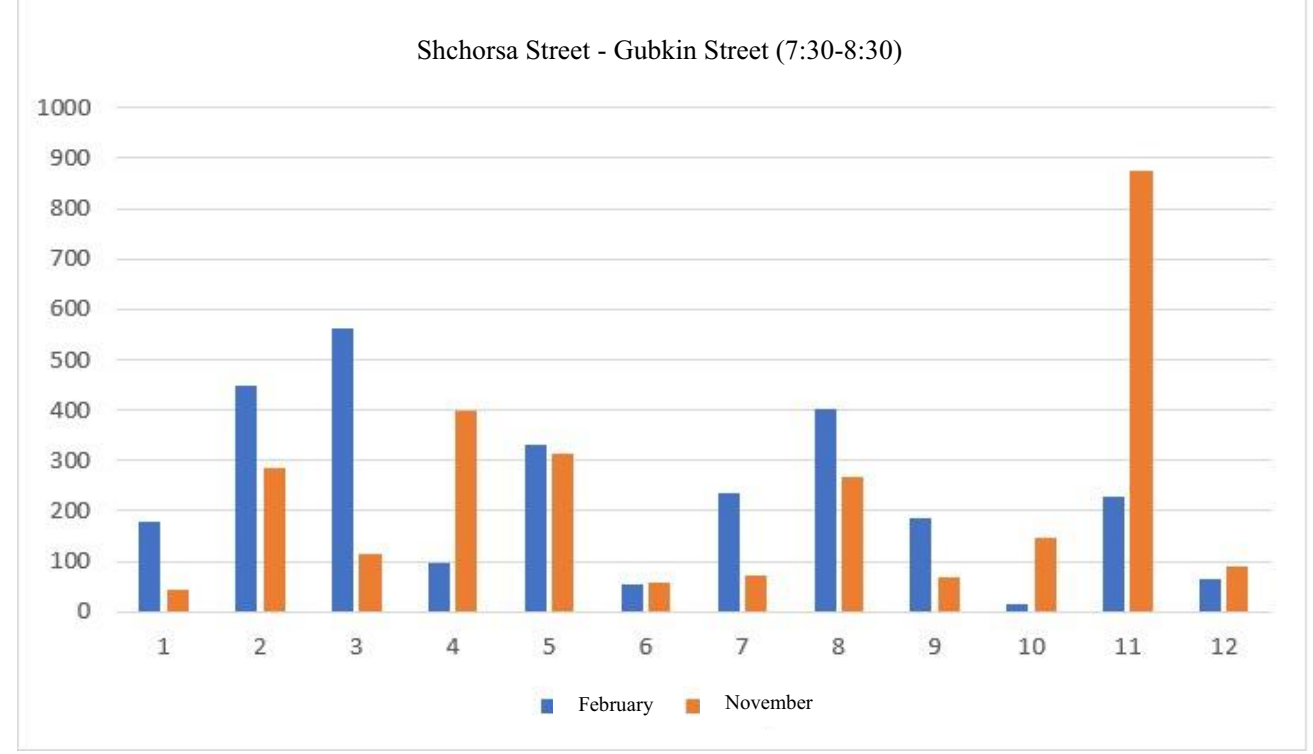

Fig. 8. Schedule of reallocation of traffic flows at the intersection of Shchorsa Street - Gubkin Street 
Using the generated ASUDD for Shchors Street, the adaptive control system for traffic light objects was turned on, which showed the following results at different intensity settings per lane, shown in Figure 9.

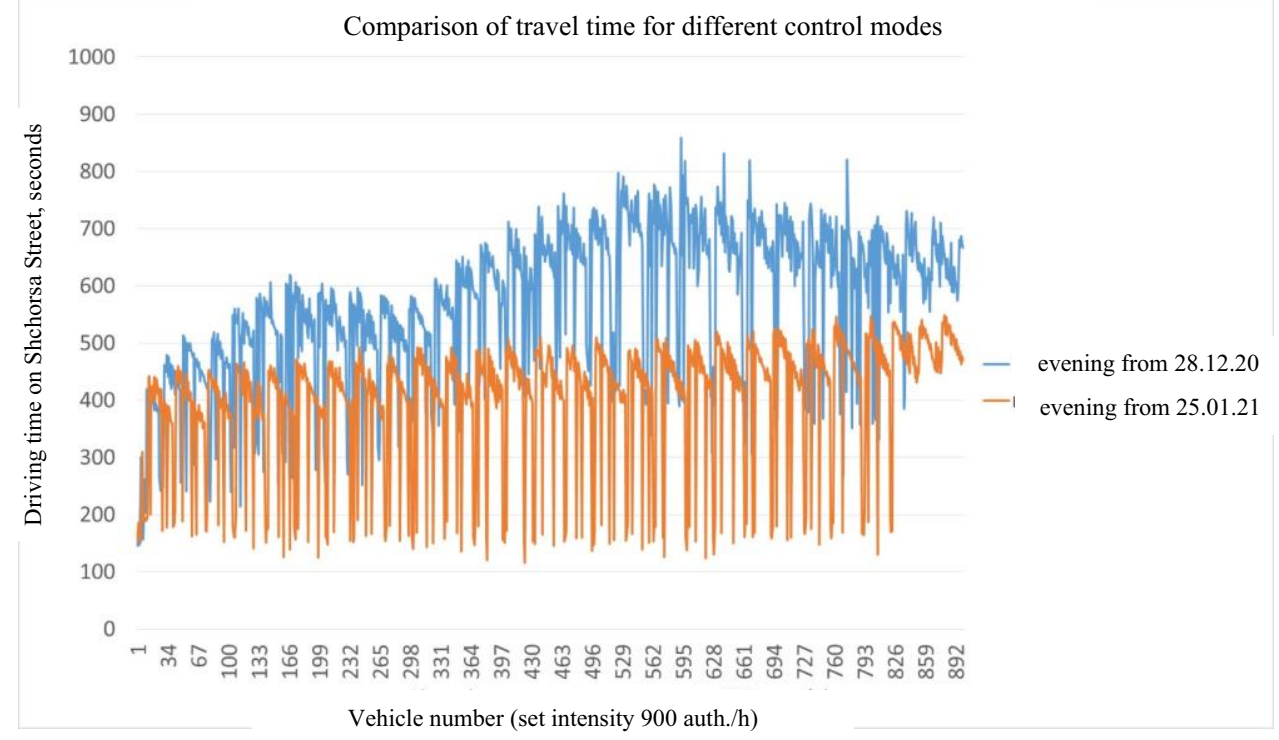

Fig. 9. Comparative work schedules of the RIPAS adaptive system on Shchorsa Street by travel time

\section{Conclusion}

To optimize traffic flows, you should use controllers and software that must meet certain requirements. The use of radar detectors allows you to monitor the traffic flow.

The adaptive system made it possible to reduce the driving time on Shchorsa Street relative to the basic settings of traffic lights from 650 seconds to 500 seconds, which is $23 \%$ of the basic indicator in the evening rush hour.

\section{References}

1. Ambartsumyan, V. A. Road traffic safety . - M: Mashinostroenie, 304 p. (1988)

2. B. B. Anokhin, O. P. Lavrentieva. Assessment of traffic conditions at different levels of road loading, Roads and bridges: sat. - Issue 18/2. - Moscow: Ros-dor, - pp. 137-150. (2006)

3. Babkov V. F. Road conditions and traffic safety: textbook. manual for universities M.: Transport, 288 p. (1982)

4. A. E. Borovskoy, A. G. Shevtsova. The real saturation flow depending on the class of a passenger car, Problems of quality and operation of motor vehicles: collection of materials of the VII International Scientific and technical Conference, Penza, May 1618, 2012 / Penza State University of Architecture and Construction-Penza: Publishing House of ADI PGUAS, p. 244-250 (2012)

5. A. E. Borovskoi, A. S. Ostapko, A. G. Shevtsova, Transport problem and various spheres of activity, Prospects of innovations in science, education and Transport 2012: Collection of Sword scientific papers based on the materials of the International Scientific and Practical Conference, Odessa, June 19-30, 2012 / Issue 2. Volume 1. Odessa: Kuprienko SV Publishing House, pp. $72-79$ (2012) 
6. Bulavina, L. V. Calculation of the throughput capacity of highways and nodes: A textbook - Ural State Technical University. univ. - Yekaterinburg: Publishing house of USTU, 267 p. (2009)

7. A. P. Vasilyev, V. M. Sidenko. Exploitation of automobile roads and organization of road traffic - M.: Transport, 304 p. (1990)

8. Vygodsky, M. Ya. Handbook of higher mathematics - M.: Ast-rel: AST, 992 p. (2002)

9. GOST R 51256-99" Technical means of organizing road traffic. Road markings. Types and basic parameters. General technical requirements".

10. GOST R 52289-2004" Technical means of organizing road traffic. Rules for the use of road signs, markings, traffic lights, road barriers and guide devices"

11. Kim S. Cameron, Robert E. Quinn Diagnostics and changes in organizational culture ; translated from English

12. Dobrenkov V. I. Kravchenko A. I. Methods of sociological research: Textbook - M.: INFRA-M, 768 p. (2006)

13. Kremenets Yu. A., Pechersky M. P., Afanasyev M. B. Technical means of organizing road traffic: Textbook for universities-MICC "Akademkniga", 279 p. (2005)

14. Methodology for assessing the cost of damaged vehicles, the cost of their restoration and damage from damage " P-03112194-0377-98. Ministry of Transport of the Russian Federation. Moscow (1998)

15. Novikov, I. A., Shevtsova A. G. Influence of changes in vehicle delays on the number of modes of operation of a traffic light object, Journal "World of transport and technological machines", State University - Educational-scientific-production Complex - Orel: Publishing House of OGTU. No. 4, pp. 62-68 (2011)

16. Problems of quality and operation of motor vehicles: materials of the VI International Scientific Journal. - tech. conf. 18-20 May 2010, Penza: PGUAS, Part 1. 356 p. (2010)

17. Highway Capacity Manual. TRB, Washington, DC, - with 122. (2000)

18. McSchane, W. and Roess R. Traffic engineering, Prentice Hall, Englewood Cliffs, New Jersey, With 312. (1990) 